Keywords

sleep disordered breathing; sympathetic; consequences

Corresponding author: Virend K. Somers, Professor of Medicine, Mayo Clinic College of Medicine, 200 First Street, SW, Rochester, MN 55905, somers.virend@mayo.edu.

Author contributions

Meghna P. Mansukhani drafted and revised the manuscript.

Shihan Wang revised the manuscript.

Virend K. Somers created the outline, drafted and supervised the writing of the manuscript.

All authors confirm that they have approved the final version of this manuscript. All persons designated as authors qualify for authorship and all those who qualify for authorship are listed.

The content is solely the responsibility of the authors and does not necessarily represent the official views of the National Institutes of Health.

Competing interests

Meghna P. Mansukhani has no competing interests.

Shihan Wang has no competing interests.

Virend K. Somers has served as a consultant for ResMed, Respicardia, Price Waterhouse Cooper, and Sorin. Dr. Somers has also received research support derived from a gift from the Respironics Foundation to the Mayo Foundation. 


\section{Chemoreflex physiology}

Hypoxemia elicits increases in ventilation with modest accompanying increases in sympathetic nerve traffic to blood vessels (Somers et al., 1989b, a; Somers et al., 1991). At the same time, inspiration and stretch of thoracic afferents have an inhibitory or buffering influence on the autonomic response to hypoxemia, so that during hypoxemia the increase in sympathetic activity is masked by the accompanying hyperventilation. Importantly, the primary response to hypoxemia is bradycardia mediated by increased cardiac vagal outflow, a response also suppressed by ventilation and activation of thoracic afferents (Angell-James \& Daly, 1975; Somers et al. 1989b, a; Somers et al. 1995). Hence when hypoxemia is accompanied by apnea, the adaptive sympathetic and vagal responses become more evident, manifesting as potentiated sympathetic vasoconstriction and vagal bradycardia (Kara et al., 2003). This simultaneous activation of central sympathetic outflow to blood vessels and vagal outflow to the heart constitutes part of what is known as the "diving reflex" (AngellJames \& Daly, 1975), a reflex that is exhibited strongly in aquatic mammals such as sea lions. The concurrent responses to hypoxemia including peripheral vasoconstriction and bradycardia enable these air breathing mammals to stay under water for extended periods.

In humans, hypoxemia and apnea occur both in physiologic conditions such as swimming and pathologic conditions such as sleep apnea (Somers et al., 2008). The clinical implications of the chemoreflex response to hypoxemia are discussed further later in this review.

Hypoxemia acts primarily through the peripheral chemoreceptors in the carotid sinus. While hypercapnia influences both the carotid body as well as central chemoreceptors in the medulla oblongata, there is evidence that the peripheral chemoreceptors, through afferent innervation, act to enhance the effect on the sensitivity of central chemoreceptors to hypercapnia (Kara et al., 2003; Blain et al., 2010; Del Rio et al., 2010). Hypercapnia also elicits increases in sympathetic outflow to peripheral blood vessels and this response is buffered by hyperventilation. The combination of hypoxemia and hypercapnia results in a potentiated sympathetic response and during apnea, due to the co-occurrence of hypoxemia and hypercapnia in the absence of ventilation, the sympathetic activation can increase synergistically (Somers et al., 1989b).

The peripheral chemoreflex responses are potentiated by catecholamines which activate receptors in the carotid bodies (Heistad et al., 1974). Dobutamine, a beta-1 agonist, has been found to enhance the ventilatory and autonomic effects of the chemoreflex in healthy human subjects (Velez-Roa et al., 2003). In addition, angiotensin II, which in turn is increased as a result of sympathetic activation from hypoxemia, can directly stimulate sympathetic nuclei located in the hypothalamus and brainstem. Many studies have demonstrated that endogenous nitric oxide (NO) plays an important role in the carotid body chemoreceptor function as an inhibitory modulator (Pimenta et al., 2013). Production of pro-inflammatory cytokines (Del Rio et al., 2012) reactive oxygen species and differential expression of hypoxia-inducible factors $1 \& 2$ in the carotid bodies (Mansukhani et al., 2014) have recently been demonstrated in animal and human studies. 
Activation of the baroreflexes has an inhibitory influence on chemoreflex gain, with inhibition of the response to hypoxemia being more marked than inhibition of the response to hypercapnia. Activation of the baroreflex is able to inhibit both ventilatory and autonomic responses to chemoreflex activation (Somers et al., 1991; Somers et al., 1992; Narkiewicz et al., 1998b). Interestingly, bradyarrhythmias induced by hypoxemia and apnea are attenuated when the baroreflexes are activated simultaneously. This speaks to the power of the reflex interaction since baroreflex activation itself induces bradycardia; thus, in the absence of an inhibitory influence from normal ventilation, rather than being unchanged or increased, the bradycardic response to chemoreflex activation is attenuated by simultaneous baroreflex activation (Somers et al., 1991; Somers et al., 1992).

These data would suggest that disease conditions that are associated with impaired baroreflex gain, such as hypertension and heart failure (Somers et al., 1991; Somers et al., 1992) would also be accompanied by exaggerated chemoreflex responses.

\section{Peripheral Chemoreflexes in Hypertension}

There is evidence suggesting potentiation of the peripheral chemoreflex in spontaneously hypertensive rats (Fukuda et al., 1987) and that the autonomic disturbance precedes the onset of hypertension (Iturriaga et al., 2010). An exaggerated ventilatory response to hypoxemia has also been noted in borderline hypertensive humans (Trzebski et al., 1982). Measures of peripheral sympathetic traffic have confirmed this heightened response to hypoxemia in borderline hypertension and demonstrated that the potentiated chemoreflexmediated sympathetic vasoconstriction was especially striking when apnea was superimposed on hypoxemia (Somers et al., 1988).

\section{Chemoreflexes in Obesity}

In order to better determine the role of the chemoreflex in disease conditions, it is important to understand the physiology of the chemoreflex in conditions such as obesity and aging, and the influence of gender. Studies in obese humans who are free of any co-existing disease show that obesity is associated with a heightened central chemoreflex response to hypercapnia. This appears to be a selective potentiation, since the response to hypoxemia is not different from that seen in normal weight control subjects (Narkiewicz et al., 1998a). The mechanism underlying this selective central chemoreflex potentiation is unclear, but may be related to the effect of leptin, which is produced by the adipocytes and increased in conditions such as obesity (Ciriello \& Moreau, 2012). These findings may shed some light on understanding the higher baseline sympathetic nerve activity in OSA subjects with metabolic syndrome compared to those without metabolic syndrome (Mansukhani et al., 2014).

Sympathetically mediated renal vasoconstriction in response to voluntary apnea was not found to be different between healthy young and older subjects in a recent study (Patel et al., 2013), although evidence on the effects of aging on the peripheral chemoreflex from previous studies is equivocal (Poulin et al., 1993; Schmidt et al., 2005). The results of another study by Patel et al. suggested that female sex hormones could dampen the effects of sympathetic vasoconstriction in the forearm induced by apnea under experimental 
conditions (Patel et al., 2014). The effect on control of breathing in pre- and postmenopausal women may be mediated by the central rather than the peripheral chemoreflex, in addition to female sex steroid hormones (Preston et al., 2009).

\section{Obstructive Sleep Apnea}

Patients with obstructive sleep apnea (OSA) have a selective enhancement of the ventilatory and autonomic responses to hypoxemia, but not to hypercapnia. The autonomic responses, specifically, peripheral sympathetic vasoconstriction and vagally mediated bradycardia, are especially evident during apnea (Narkiewicz et al., 1998b; Iturriaga et al., 2005). This selective enhancement in peripheral chemoreflex gain is not explained by hypertension alone, since the responses described above were manifest in normotensive OSA subjects (Narkiewicz et al., 1998b). Furthermore, although patients with OSA are often obese, the chemoreflex physiology appears to differ from that seen in obesity, where it is the chemoreflex response to carbon dioxide that is accentuated (Narkiewicz et al., 1999).

Patients with OSA undergo repetitive episodes of hypoxemia and sometimes hypercapnia during disordered breathing events. Consequently, during these obstructive breathing events sympathetic vasoconstriction is striking, with increases in blood pressure to very high levels (Figure 1). While simultaneous bradycardia is often evident, especially toward the end of an apnea, some patients develop severe bradyarrhythmias including Mobitz type II, complete heart block, and even asystole lasting for 10 seconds or more (Somers et al., 1995). This bradyarrhythmic response is more frequent in those who experience more profound nocturnal oxygen desaturation (Koehler et al., 2000) and is mediated via the chemoreflex. Thus, the first line of treatment is prevention of apnea rather than placement of a permanent pacemaker.

Recent studies have suggested that vascular factors, sleep deprivation and impaired exercise tolerance could also play a role in the sympathetic activation seen in OSA (Mansukhani et al., 2014).

The chemoreflex-mediated neural circulatory responses to OSA have other wide ranging consequences. These include first, that the physiologic fall in blood pressure during sleep is attenuated or abolished, resulting in a "non-dipper" blood pressure profile. These patients, whose blood pressure does not fall at night, are known to be at increased long-term risk for cardiovascular disease (Endeshaw et al., 2009). Not only has OSA been found to be closely associated with baseline hypertension and incident hypertension in a dose-dependent fashion but has also been noted to be the most common secondary cause of increased blood pressure in subjects with resistant hypertension (Mansukhani et al., 2014).

Second, the hypoxemia occurring in the setting of hypercapnia, increased sympathetic drive, and other apnea induced stresses, is known to elicit cardiac ischemia with accompanying ST segment changes (Mooe et al., 2000), and may also contribute to the increased likelihood of nocturnal myocardial infarction in patients with OSA (Kuniyoshi et al., 2008).

Third, simultaneous sympathetic and vagal activation in the setting of hypoxemia may increase the likelihood of atrial fibrillation and may also explain, at least in part, the 
increased risk of potentially lethal arrhythmias occurring at night requiring the appropriate firing of implanted cardiac defibrillators (Zeidan-Shwiri et al., 2011). Additionally, the increased likelihood of cardiac ischemia and cardiac arrhythmias are likely contributors to the heightened risk for nocturnal sudden death in patients with OSA (Gami et al., 2005) (Figure 2).

Treatment of OSA with CPAP, tracheostomy and oral appliances has been shown to decrease urinary and serum catecholamine levels, muscle sympathetic nerve activity, nighttime and 24-hour blood pressures (Mansukhani et al., 2014). Those with comorbid diabetes mellitus and severe OSA appear to demonstrate a greater decline in catecholamine levels. Decreases in 24-hour mean blood pressure have also been noted in subjects with prehypertension and resistant hypertension after long-term CPAP use in some recent studies (Mansukhani et al., 2014).

\section{Central Sleep Apnea}

Central sleep apnea (CSA) occurs predominantly in patients with heart failure, where it may sometimes manifest as a crescendo-decrescendo breathing pattern called Hunter Cheyne Stokes breathing(Javaheri \& Corbett, 1998). Patients with heart failure also have a propensity towards heightened sensitivity to arterial carbon dioxide (PaCO2). It is thought that this heightened $\mathrm{PaCO} 2$ responsiveness may be an important factor underlying the unstable breathing pattern that results in central apneas during sleep in heart failure patients (Javaheri \& Corbett, 1998).

Although patients with systolic and diastolic heart failure have high levels of sympathetic drive at baseline, during central apneas sympathetic outflow increases even further (van de Borne et al., 1998). In heart failure patients with CSA, plasma and urinary catecholamines are higher than in heart failure patients without CSA (Mansfield et al., 2003; Solin et al., 2003). Interestingly, the increased sympathetic activity appears to be related to heart failure severity and not CSA severity (Mansfield et al., 2003). This increase in adrenergic drive in heart failure patients with CSA may help explain, in part, the increased mortality risk in this patient population (Levy et al., 2013).

Lanfranchi et al. reported autonomic dysfunction, as measured by decreased heart rate variability, in patients with CSA (Lanfranchi \& Somers, 2003). Additionally, treatment of OSA with CPAP in patients with congestive heart failure has been shown to reduce this autonomic dysfunction (Gilman et al., 2008). In a study of 216 patients with stable advanced heart failure, with 21 (9\%) patients suffering a cardiac arrest over a 4-year follow up period, the most common electrocardiographic rhythm preceding sudden cardiac arrest was noted to be severe bradycardia, which is frequently seen in patients with OSA (Luu et al., 1989). While these studies reveal some preliminary insights into the potential mechanisms which may result in increased mortality in heart failure patients with coexistent CSA/OSA, studies to further elucidate and confirm these findings are required. 


\section{Conclusions}

Chemoreflex physiology is important in maintaining homeostasis, particularly during physiologic stresses such as swimming and ascent to higher altitude. However, in pathological conditions, the activity of the chemoreflex may be abnormal and may contribute to cardiovascular pathophysiology and adverse outcomes. Recognition of the role of the chemoreflex in disease and the mechanisms by which the chemoreflex may potentiate adverse events may allow us to identify strategies for both prevention and treatment. Novel methods to quantify and alter the chemoreflex response in sleep apnea may help individualize these prevention and treatment strategies.

\section{Acknowledgments}

\section{Funding}

This work was supported by the National Heart, Lung, and Blood Institute of the National Institutes of Health under Award Number R01HL065176.

\section{References}

Angell-James JE, Daly MB. Some aspects of upper respiratory tract reflexes. Acta Otolaryngol. 1975; 79:242-252. [PubMed: 1136764]

Blain GM, Smith CA, Henderson KS, Dempsey JA. Peripheral chemoreceptors determine the respiratory sensitivity of central chemoreceptors to CO(2). J Physiol. 2010; 588:2455-2471. [PubMed: 20421288]

Ciriello J, Moreau JM. Leptin signaling in the nucleus of the solitary tract alters the cardiovascular responses to activation of the chemoreceptor reflex. Am J Physiol Regul Integr Comp Physiol. 2012; 303:R727-736. [PubMed: 22914750]

Del Rio R, Moya EA, Iturriaga R. Carotid body and cardiorespiratory alterations in intermittent hypoxia: the oxidative link. Eur Respir J. 2010; 36:143-150. [PubMed: 19996187]

Del Rio R, Moya EA, Parga MJ, Madrid C, Iturriaga R. Carotid body inflammation and cardiorespiratory alterations in intermittent hypoxia. Eur Respir J. 2012; 39:1492-1500. [PubMed: 22183481]

Endeshaw YW, White WB, Kutner M, Ouslander JG, Bliwise DL. Sleep-disordered breathing and 24hour blood pressure pattern among older adults. J Gerontol A Biol Sci Med Sci. 2009; 64:280-285. [PubMed: 19196901]

Fukuda Y, Sato A, Trzebski A. Carotid chemoreceptor discharge responses to hypoxia and hypercapnia in normotensive and spontaneously hypertensive rats. J Auton Nerv Syst. 1987; 19:111. [PubMed: 3598046]

Gami AS, Howard DE, Olson EJ, Somers VK. Day-night pattern of sudden death in obstructive sleep apnea. N Engl J Med. 2005; 352:1206-1214. [PubMed: 15788497]

Gilman MP, Floras JS, Usui K, Kaneko Y, Leung RS, Bradley TD. Continuous positive airway pressure increases heart rate variability in heart failure patients with obstructive sleep apnoea. Clin Sci (Lond). 2008; 114:243-249. [PubMed: 17824846]

Heistad DD, Abboud FM, Mark AL, Schmid PG. Interaction of baroreceptor and chemoreceptor reflexes. Modulation of the chemoreceptor reflex by changes in baroreceptor activity. J Clin Invest. 1974; 53:1226-1236. [PubMed: 4825222]

Iturriaga R, Moya EA, Del Rio R. Cardiorespiratory alterations induced by intermittent hypoxia in a rat model of sleep apnea. Adv Exp Med Biol. 2010; 669:271-274. [PubMed: 20217364]

Iturriaga R, Rey S, Del Rio R. Cardiovascular and ventilatory acclimatization induced by chronic intermittent hypoxia: a role for the carotid body in the pathophysiology of sleep apnea. Biol Res. 2005; 38:335-340. [PubMed: 16579514] 
Javaheri S, Corbett WS. Association of low $\mathrm{PaCO} 2$ with central sleep apnea and ventricular arrhythmias in ambulatory patients with stable heart failure. Ann Intern Med. 1998; 128:204-207. [PubMed: 9454528]

Kara T, Narkiewicz K, Somers VK. Chemoreflexes--physiology and clinical implications. Acta Physiol Scand. 2003; 177:377-384. [PubMed: 12609009]

Koehler U, Becker HF, Grimm W, Heitmann J, Peter JH, Schafer H. Relations among hypoxemia, sleep stage, and bradyarrhythmia during obstructive sleep apnea. Am Heart J. 2000; 139:142-148. [PubMed: 10618575]

Kuniyoshi FH, Garcia-Touchard A, Gami AS, Romero-Corral A, van der Walt C, Pusalavidyasagar S, Kara T, Caples SM, Pressman GS, Vasquez EC, Lopez-Jimenez F, Somers VK. Day-night variation of acute myocardial infarction in obstructive sleep apnea. J Am Coll Cardiol. 2008; 52:343-346. [PubMed: 18652941]

Lanfranchi PA, Somers VK. Sleep-disordered breathing in heart failure: characteristics and implications. Respir Physiol Neurobiol. 2003; 136:153-165. [PubMed: 12853007]

Levy P, Ryan S, Oldenburg O, Parati G. Sleep apnoea and the heart. Eur Respir Rev. 2013; 22:333352. [PubMed: 23997061]

Luu M, Stevenson WG, Stevenson LW, Baron K, Walden J. Diverse mechanisms of unexpected cardiac arrest in advanced heart failure. Circulation. 1989; 80:1675-1680. [PubMed: 2598430]

Mansfield D, Kaye DM, Brunner La Rocca H, Solin P, Esler MD, Naughton MT. Raised sympathetic nerve activity in heart failure and central sleep apnea is due to heart failure severity. Circulation. 2003; 107:1396-1400. [PubMed: 12642360]

Mansukhani MP, Kara T, Caples SM, Somers VK. Chemoreflexes, sleep apnea, and sympathetic dysregulation. Curr Hypertens Rep. 2014; 16:476. [PubMed: 25097113]

Mooe T, Franklin KA, Wiklund U, Rabben T, Holmstrom K. Sleep-disordered breathing and myocardial ischemia in patients with coronary artery disease. Chest. 2000; 117:1597-1602. [PubMed: 10858389]

Narkiewicz K, Kato M, Pesek CA, Somers VK. Human obesity is characterized by a selective potentiation of central chemoreflex sensitivity. Hypertension. 1999; 33:1153-1158. [PubMed: 10334803]

Narkiewicz K, van de Borne PJ, Cooley RL, Dyken ME, Somers VK. Sympathetic activity in obese subjects with and without obstructive sleep apnea. Circulation. 1998a; 98:772-776. [PubMed: 9727547]

Narkiewicz K, van de Borne PJ, Montano N, Dyken ME, Phillips BG, Somers VK. Contribution of tonic chemoreflex activation to sympathetic activity and blood pressure in patients with obstructive sleep apnea. Circulation. 1998b; 97:943-945. [PubMed: 9529260]

Patel HM, Heffernan MJ, Ross AJ, Muller MD. Sex differences in forearm vasoconstrictor response to voluntary apnea. Am J Physiol Heart Circ Physiol. 2014; 306:H309-316. [PubMed: 24322616]

Patel HM, Mast JL, Sinoway LI, Muller MD. Effect of healthy aging on renal vascular responses to local cooling and apnea. J Appl Physiol (1985). 2013; 115:90-96. [PubMed: 23640587]

Pimenta E, Gordon RD, Stowasser M. Salt, aldosterone and hypertension. J Hum Hypertens. 2013; 27:1-6. [PubMed: 22785050]

Poulin MJ, Cunningham DA, Paterson DH, Kowalchuk JM, Smith WD. Ventilatory sensitivity to CO2 in hyperoxia and hypoxia in older aged humans. J Appl Physiol (1985). 1993; 75:2209-2216. [PubMed: 8307881]

Preston ME, Jensen D, Janssen I, Fisher JT. Effect of menopause on the chemical control of breathing and its relationship with acid-base status. Am J Physiol Regul Integr Comp Physiol. 2009; 296:R722-727. [PubMed: 19091912]

Schmidt H, Francis DP, Rauchhaus M, Werdan K, Piepoli MF. Chemo- and ergoreflexes in health, disease and ageing. Int J Cardiol. 2005; 98:369-378. [PubMed: 15708167]

Solin P, Kaye DM, Little PJ, Bergin P, Richardson M, Naughton MT. Impact of sleep apnea on sympathetic nervous system activity in heart failure. Chest. 2003; 123:1119-1126. [PubMed: 12684302]

Somers VK, Dyken ME, Clary MP, Abboud FM. Sympathetic neural mechanisms in obstructive sleep apnea. J Clin Invest. 1995; 96:1897-1904. [PubMed: 7560081] 
Somers VK, Dyken ME, Mark AL, Abboud FM. Parasympathetic hyperresponsiveness and bradyarrhythmias during apnoea in hypertension. Clin Auton Res. 1992; 2:171-176. [PubMed: 1498563]

Somers VK, Mark AL, Abboud FM. Potentiation of sympathetic nerve responses to hypoxia in borderline hypertensive subjects. Hypertension. 1988; 11:608-612. [PubMed: 3391673]

Somers VK, Mark AL, Abboud FM. Interaction of baroreceptor and chemoreceptor reflex control of sympathetic nerve activity in normal humans. J Clin Invest. 1991; 87:1953-1957. [PubMed: 2040688]

Somers VK, Mark AL, Zavala DC, Abboud FM. Contrasting effects of hypoxia and hypercapnia on ventilation and sympathetic activity in humans. J Appl Physiol (1985). 1989a; 67:2101-2106. [PubMed: 2513316]

Somers VK, Mark AL, Zavala DC, Abboud FM. Influence of ventilation and hypocapnia on sympathetic nerve responses to hypoxia in normal humans. J Appl Physiol (1985). 1989b; 67:2095-2100. [PubMed: 2513315]

Somers VK, White DP, Amin R, Abraham WT, Costa F, Culebras A, Daniels S, Floras JS, Hunt CE, Olson LJ, Pickering TG, Russell R, Woo M, Young T. Sleep apnea and cardiovascular disease: an American Heart Association/american College Of Cardiology Foundation Scientific Statement from the American Heart Association Council for High Blood Pressure Research Professional Education Committee, Council on Clinical Cardiology, Stroke Council, and Council On Cardiovascular Nursing. In collaboration with the National Heart, Lung, and Blood Institute National Center on Sleep Disorders Research (National Institutes of Health). Circulation. 2008; 118:1080-1111. [PubMed: 18725495]

Trzebski A, Tafil M, Zoltowski M, Przybylski J. Increased sensitivity of the arterial chemoreceptor drive in young men with mild hypertension. Cardiovasc Res. 1982; 16:163-172. [PubMed: 6805956]

van de Borne P, Oren R, Abouassaly C, Anderson E, Somers VK. Effect of Cheyne-Stokes respiration on muscle sympathetic nerve activity in severe congestive heart failure secondary to ischemic or idiopathic dilated cardiomyopathy. Am J Cardiol. 1998; 81:432-436. [PubMed: 9485132]

Velez-Roa S, Kojonazarov B, Ciarka A, Godart P, Naeije R, Somers VK, van de Borne P. Dobutamine potentiates arterial chemoreflex sensitivity in healthy normal humans. Am J Physiol Heart Circ Physiol. 2003; 285:H1356-1361. [PubMed: 12750069]

Zeidan-Shwiri T, Aronson D, Atalla K, Blich M, Suleiman M, Marai I, Gepstein L, Lavie L, Lavie P, Boulos M. Circadian pattern of life-threatening ventricular arrhythmia in patients with sleepdisordered breathing and implantable cardioverter-defibrillators. Heart Rhythm. 2011; 8:657-662. [PubMed: 21185402] 


\section{NEW FINDINGS}

\section{What is the topic of this review?}

This review summarizes chemoreflex physiology in health and disease with specific focus on chemoreflex-mediated pathophysiology in obstructive and central sleep apnea.

\section{What advances does it highlight?}

Chemoreflex mechanisms are thought to contribute significantly to the pathophysiology and adverse outcomes seen in sleep apnea. Clinical implications of altered chemoreflex function in sleep apnea from recent studies in humans, including cardiac arrhythmias, coronary artery disease, systolic/diastolic heart failure as well as sudden cardiac death are highlighted. 
SNA

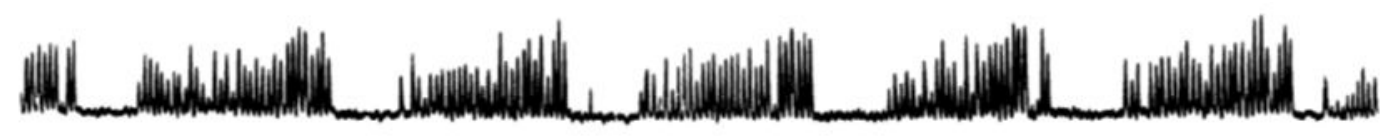

RESP
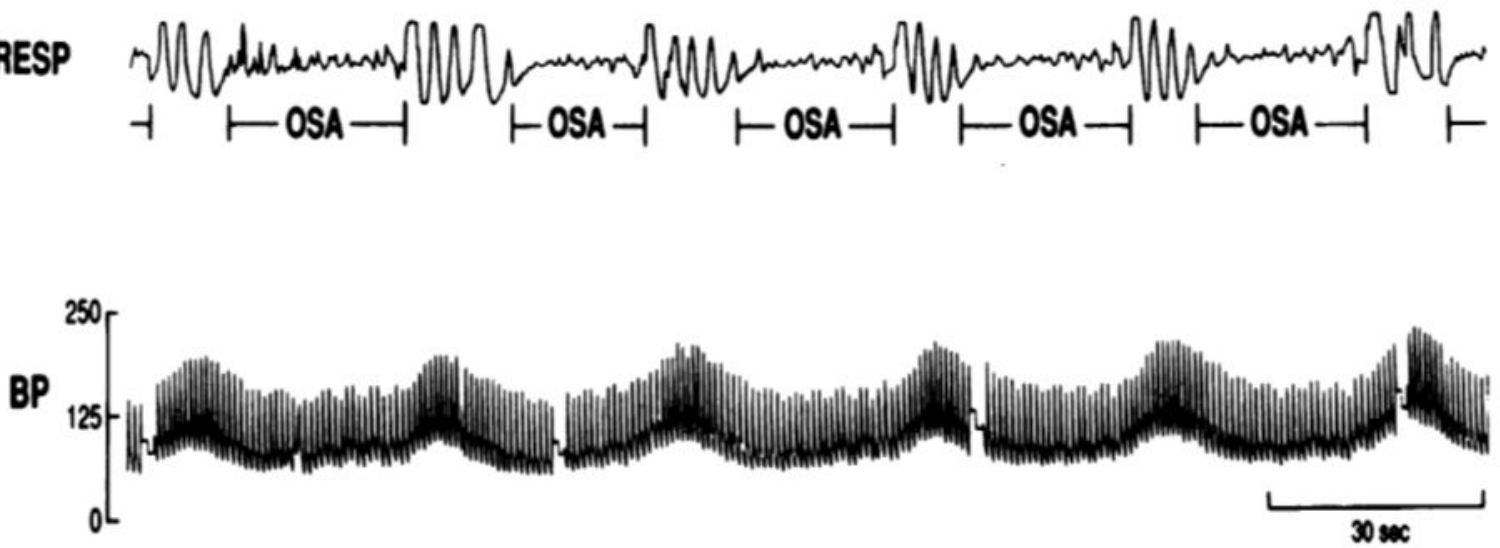

Figure 1.

Recordings of sympathetic nerve activity (SNA), respiration (RESP) and blood pressure (BP) during 3 minutes of non-rapid eye movement sleep, showing significant oscillations in SNA and BP in response to obstructive sleep apnea (OSA).

Reproduced with permission from Somers et al. 1995 (Somers et al., 1995). 


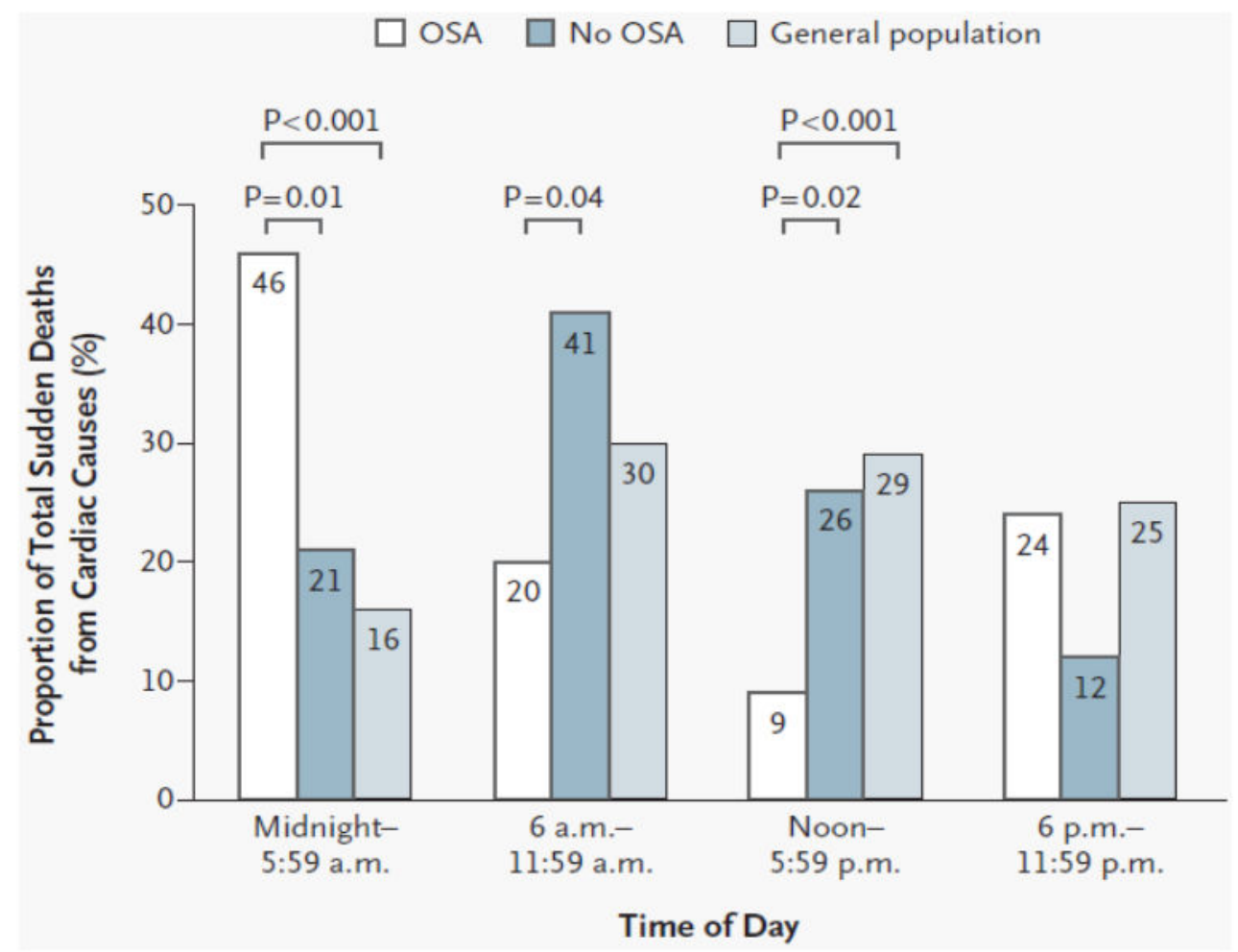

Figure 2.

Day-night pattern of sudden cardiac death in subjects with obstructive sleep apnea (OSA), without OSA and in the general population.

Reproduced with permission from Gami et al. 2005 (Gami et al., 2005). 